\title{
Zebrafish brain RNA sequencing reveals that cell adhesion molecules are critical in brain aging
}

\author{
Begün Erbaba, b,c Özge Pelin Burhan ${ }^{a, b, c}$, Naz Şerifoğlu ${ }^{a, b, c, d}$, Bihter Muratoğlu ${ }^{\text {d, }}$ \\ Fatma Kahveci ${ }^{\mathrm{e}}$, Michelle M. Adams ${ }^{\mathrm{a}, \mathrm{b}, \mathrm{c}, \mathrm{f}, \mathrm{g}}$, Ayça Arslan-Ergüll, ${ }^{\mathrm{d}, *}$ \\ a Interdisciplinary Graduate Program in Neuroscience, Aysel Sabuncu Brain Research Center, Bilkent University, Ankara, Turkey \\ ${ }^{\mathrm{b}}$ UNAM - National Nanotechnology Research Center and Institute of Materials Science and Nanotechnology, Bilkent University, Ankara, Turkey \\ ${ }^{\mathrm{c}}$ Department of Molecular Biology and Genetics Zebrafish Facility, Bilkent University, Ankara, Turkey \\ ${ }^{\mathrm{d}}$ Stem Cell Research and Application Center, Hacettepe University, Ankara, Turkey \\ ${ }^{\mathrm{e}}$ Department of Computer Engineering, Bilkent University, Ankara, Turkey \\ ${ }^{\mathrm{f}}$ Department of Psychology, Bilkent University, Ankara, Turkey \\ ${ }^{\mathrm{g}}$ UMRAM, National Magnetic Resonance Research Center, Bilkent University, Ankara, Turkey
}

\section{A R T I C L E I N F O}

Article history:

Received 3 July 2019

Received in revised form 27 February 2020

Accepted 19 April 2020

Available online 12 May 2020

\section{Keywords:}

Zebrafish

Brain aging

Cell adhesion molecules

RNA sequencing

\begin{abstract}
A B S T R A C T
Brain aging is a complex process, which involves multiple pathways including various components from cellular to molecular. This study aimed to investigate the gene expression changes in zebrafish brains through young-adult to adult, and adult to old age. RNA sequencing was performed on isolated neuronal cells from zebrafish brains. The cells were enriched in progenitor cell markers, which are known to diminish throughout the aging process. We found 176 statistically significant, differentially expressed genes among the groups, and identified a group of genes based on gene ontology descriptions, which were classified as cell adhesion molecules. The relevance of these genes was further tested in another set of zebrafish brains, human healthy, and Alzheimer's disease brain samples, as well as in Allen Brain Atlas data. We observed that the expression change of 2 genes, GJC2 and ALCAM, during the aging process was consistent in all experimental sets. Our findings provide a new set of markers for healthy brain aging and suggest new targets for therapeutic approaches to neurodegenerative diseases.
\end{abstract}

(c) 2020 Elsevier Inc. All rights reserved.

\section{Introduction}

The brain is sexually dimorphic in its function, and it shows transcriptional profile changes during a lifetime. Identifying the genetic pathways that are altered during the aging process would enable us to understand the mechanisms related to brain aging. Determining how similar neurodegenerative processes like Alzheimer's (AD) or Parkinson's disease are to healthy brain aging, and finding a therapeutic or prevention strategy for them are critical. These diseases bring a considerable burden to patients and caregivers. However, to interpret the diseased state, we must first have a comprehensive understanding of the healthy aging brain. To date, the human lifespan has elongated, and the same should be possible for the human health span. One of the methods that provide a thorough examination of the molecular and cellular aspects of the brain is RNA sequencing. It is widely used for humans and animals, with numerous different approaches. RNA sequencing data from

\footnotetext{
* Corresponding author at: Stem Cell Research and Application Center, Hacettepe University, Ankara, Turkey. Tel.: +903123052821.

E-mail address: aycaergul@hacettepe.edu.tr (A. Arslan-Ergül).
}

the aging human brain is accessible to everyone through The Aging, Dementia, and Traumatic Brain Injury (TBI) Study (http://aging. brain-map.org). In this study, human brain regions were sequenced, from donors of 78-100+ ages, with defined dementia or TBI status.

Various factors have been emphasized in the literature having impacts on the aging process, from molecules to cellular components and pathways. To begin with, complement system genes were discovered as biomarkers for aging (Bae et al., 2018). Likewise, immune system genes were found to be upregulated in the hippocampus during aging (lanov et al., 2017). In another study, micro RNA (miRNA)s were examined for their roles in aging. A specific miRNA, miR-34, for example, was observed to be effective in preventing neurodegeneration (Kennerdell et al., 2018). Another factor affecting aging is post-transcriptional regulation. Increases in RNA editing throughout aging is a conserved feature in primates (Li et al., 2013). It was shown that intron retention plays a differential role in regulating biological functions at different stages of aging (Adusumalli et al., 2019). Analogously, splicing patterns were also investigated during aging. Although most of the splicing is confined to developmental stages, some still persist during aging (Mazin 
et al., 2013). Last but not the least, the autophagy-lysosomal-related pathways stood out in AD in the dorsolateral prefrontal cortex (Raj et al., 2018). To overcome the above-mentioned deteriorations occurring with advanced age, it is therefore critical to keep track of identifying new potential therapeutic targets for intervention of AD. Such another advancement is the restoration of the neural stem cell (NSC) proliferative ability via interleukin-4 recovering hampered plasticity due to AD (Papadimitriou et al., 2018).

There is also an inter-individual variability in gene expression, and the heterogeneity increases as the age increases. A recent study found that middle-aged women and Alzheimer's patients had more similar patterns in the prefrontal cortex than that with the younger women (Sanfilippo et al., 2019). As suggested by Kedlian et al. (2019), this gene expression variation occurring with advanced age is not solely restricted to a specific pathway, but instead it is distributed throughout diverse biological pathways.

An earlier study examining the existing databases to find a common pathway contributing to $\mathrm{AD}$ pointed out the cell adhesion molecule pathway to be the only consistent one (Liu et al., 2012). In addition, cell adhesion molecules, as a gene ontology (GO) biological process category, were found among the categories that are significantly enriched in genes showing consistent upregulation during postnatal development and downregulation in aging (Dönertaş et al., 2017). In like manner, cell-adhesion-related genes along with the genes having roles in cell membrane, regulation of neurogenesis, and long-term potentiation were demonstrated to be downregulating with age in the rat hippocampus (Pereira et al., 2017). Similarly, Frahm et al. (2017) showed that focal adhesion genes are downregulated during aging. Another study analyzing 2 whole-genome $\mathrm{AD}$ transcriptome data and 4 brain expression genome-wide association study datasets revealed that cis-regulatory single-nucleotide polymorphisms are enriched in cell adhesion molecules pathway (Bao et al., 2015).

The wet laboratory experiments in this study were performed using zebrafish as model organism. Zebrafish has human orthologs for more than 10,000 genes (Howe et al., 2013) and ages gradually (Kishi 2014). In the zebrafish brain, neurogenesis continues throughout the lifespan (Kizil, 2018). Furthermore, they can repair a damage to the optic tectum and retain visual capacity, even at older ages. However, in old fish, the original number of regenerating axons and the outgrowth is diminished, compared to young animals (Van Houcke et al., 2017). Although it has been used widely in biological research, most of the experiments are performed in larval or young zebrafish (younger than 6 months). However, it is possible to study zebrafish at older ages ( $>24$ months). For example, our group analyzed the brains of fish that were 34-43 months old (Karoglu et al., 2017). Also, we previously performed a microarray analysis using individual zebrafish whole brains (Arslan-Ergul and Adams, 2014). There we examined young (7.5-8.5 months) and old (31-36 months) fish brains comparing the gene expression differences in young versus old, and male versus female brains. By using GO analysis, we found that neurogenesis, neuron formation, and brain development related gene expressions differed between young and old, as well as male and female brains.

The purpose of this study is to reveal the gene expression differences in the aging zebrafish brain by using neural cell populations and comparing these to human brain. For this, we extracted cells from brains of young-adult ( 3 months old), adult (5.5-8.5 months old), and old (26-31 months old) zebrafish and performed RNA sequencing. Following data analysis, we obtained a list of genes whose expressions were significantly changing with age. After testing our gene list in whole zebrafish brains, human brain samples, and Allen Brain Atlas data, we concluded that cell adhesion molecules, more specifically ALCAM (ALCAM; human, Alcamb; zebrafish) and GJC2 (GJC2; human, Cx47; zebrafish), are critical during brain aging. To our knowledge and according to Gene Expression Omnibus datasets, this is the first RNA sequencing data in old zebrafish brains and comparison of this data to human brain samples.

\section{Methods}

\subsection{Cell extraction from the whole brain}

The cell extraction and tissue culturing procedure from zebrafish brains were adapted from Kizil laboratory special thanks to Christos Papadimitriou and Dr Çağhan Kizil. In order for cell extraction from zebrafish brains, Miltenyi Biotec Neural Tissue Dissociation Kit (130-092-628) was used. Briefly, fish were washed in $70 \%$ ethanol, and brain dissection was performed as described previously (Arslan-Ergul et al., 2016), except for the fact that it was performed in Dulbecco's phosphate buffered saline (DPBS) $+1 \%$ penicillin-streptomycin $+1 \%$ anti-anti solution (all from Gibco). Up to 5 brains per reaction, individual brains were pooled in isolation medium containing $4 \mathrm{~mL}$ Leibowitzs (L) 15 medium and $40 \mu \mathrm{L}$ penstrep $1 \%$. Enzyme mixture 1 was prepared as $25 \mu \mathrm{L}$ papain enzyme in $950 \mu \mathrm{L}$ enzyme buffer, and added onto the brains in isolation medium and incubated in this solution at $28^{\circ} \mathrm{C}$ for 25 minutes. Then, enzyme mixture 2 ( $5 \mu \mathrm{L}$ enzyme A and $10 \mu \mathrm{L}$ buffer $\mathrm{Y}$ ) was added onto the brain tissue mixture and similarly incubated in this solution at $28^{\circ} \mathrm{C}$ for 25 minutes. After triturated glass pipettes were washed one after the other with first DPBS, then $70 \%$ ethanol, then again with DPBS, the brain tissue mixture was passed through these pipettes 20 times for homogenization. Lysates were then passed through $70 \mu \mathrm{m}$ strainers for single cell dissociation and washed with washing buffer (L15 medium supplemented with 5\% fetal bovine serum (FBS), 1\% pen-strep, and 1\% anti-anti solution). Finally, the lysates were centrifuged, the pellet was dissolved in washing buffer, and then centrifuged again. The final pellet was dissolved in culture medium (L15 supplemented with 5\% FBS, 1\% pen-strep, $20 \mathrm{ng} / \mathrm{mL}$ epidermal growth factor, and $20 \mathrm{ng} / \mathrm{mL}$ basic fibroblast growth factor). At the end, cells were incubated in $28^{\circ} \mathrm{C}$ incubator without $\mathrm{CO}_{2}$. The medium was renewed every other day by half. Cells were plated in CellBIND (Corning) flasks.

\subsection{Animals}

Wild-type $A B$ strain, zebrafish were used in the experiments. Animals were fed twice a day with dry food and 3 times a week with artemia and kept in standard conditions. The methods used in this study were approved by the Bilkent University Animal Ethics Committee with the decisions 2014/18 and 2016/1.

\subsection{RNA isolation}

Total RNAs were isolated from the scraped cell cultures, using Qiagen's RNeasy Mini Kit according to the manufacturer's instructions. The isolation protocol was followed by DNase treatment with Ambion TURBO DNA-free Kit from Thermo Fisher Scientific. Human RNA samples were obtained from Biochain (USA). Healthy RNA samples (code: R1234035-P) were pooled from 5 donors of ages 21, 24, 26, 26, and 66. Alzheimer RNA sample (code: R1236035Alz50) was from an Alzheimer patient of age 87. As commercially indicated, all human samples were collected from males.

\subsection{RNA sequencing}

For these experiments, RNA samples were sent to TUBITAKMAM Gebze Laboratories. There, Illumina HiSeq 2500 was used according to its routine operating steps. Briefly, RNA libraries were 
prepared using TruSeq Stranded Total RNA Library Prep Human/ Mouse/Rat (ILLUMINA), which also supports zebrafish, according to the manufacturer's protocol. The first step of the library preparation was the removal of cytoplasmic ribosomal RNA using biotinylated, target-specific oligos combined with Ribo-Zero ribosomal RNA removal beads. Following this depletion, the RNA was fragmented into small pieces using divalent cations under elevated temperature. The cleaved RNA fragments were copied into first strand complementary (c) DNA using reverse transcriptase and random primers, followed by second strand cDNA synthesis using DNA polymerase I and RNase $\mathrm{H}$. Double-stranded cDNA was subjected to the A-tailing and barcoding indices were added via ligation enzyme. All the samples were single indexed. The products were then purified and enriched with polymerase chain reaction (PCR) to create the final cDNA library.

Data analysis was performed by our group members and Novogene Ltd (China). In brief, raw FASTQ files were cleaned off from the adapters, Q20, Q30, and GC content were calculated. In the downstream analyses, clean data with high quality were used. Index of the reference genome was built using Bowtie v2.2.3, and paired-end clean reads were aligned using TopHat v2.0.12. Fragments per kilobase of transcript was calculated after read numbers mapped to each gene via HTSeq v0.6.1. Differential expression analysis was performed with DESeq R package (1.18.0). Genes with an adjusted $p$-value $<0.05$ (Benjamini and Hochberg approach) assigned as differentially expressed. GO enrichment analysis was implemented by the GOSeq R package (Ashburner et al., 2000; Young et al., 2010), with corrected $p$-value $<0.05$. Pathway and process enrichment analysis was done in Metascape (Zhou et al., 2019). All the raw and processed data were uploaded to Gene Expression Omnibus and can be accessed through the record GSE133436.

\subsection{Real-time PCR}

We used Roche Transcriptor HiFi cDNA Synthesis Kit to synthesize cDNA. For quantitative (q) PCR experiments, we used Roche FastStart Essential DNA Green Master in a LightCycler 480 machine and SensiFAST SYBR Mix in a Mic PCR from Biomolecular Systems. The primers used are given in Supplementary Table 1.

\subsection{Statistics}

All statistics and graphics were performed in Prism 8 for macOS, version 8.1.1. For the experiments performed on zebrafish brain cells, there were 3 samples: old, adult, and young-adult. Hence, we applied ordinary 2-way analysis of variance, followed by Tukey's multiple comparison test and $p<0.05$ was considered significant. For the data whole zebrafish brains and Alzheimer samples, there were 2 groups: 7 and 17 months old fish, and healthy and Alzheimer samples. Accordingly, we applied the 2 -tailed $t$-test. For all tests, $p<$ 0.05 was considered significant.

\section{Results}

\subsection{Gene expression profiling reveals distinct grouping}

In this study, we aimed to obtain cell suspensions from zebrafish brain of different ages. Assembling cohorts of young-adult (3 months), adult (5.5-8.5 months), and old (26-31 months) zebrafish (Table 1), we obtained a progenitor-enriched cell culture from the brains of these fish and did RNA sequencing from the total RNA (Fig. 1A). Progenitor state of these samples was confirmed via qPCR by measuring nestin, sox2, neun, s100b, and tmem119 (Fig. 1B). Nestin was used as a marker for proliferating precursors (Mahler
Table 1

Characteristics of the samples

\begin{tabular}{lll}
\hline Sample & Age & Pool \\
\hline Old1 & $26-28$ months old & 5 brains \\
Old2 & $30-31$ months old & 5 brains \\
Old3 & $30-31$ months old & 5 brains \\
Adult1 & 8.5 months old & 5 brains \\
Adult2 & 5.5 months old & 5 brains \\
Adult3 & 5.5 months old & 5 brains \\
Young-adult1 & 3 months old & 10 brains \\
Young-adult2 & 3 months old & 10 brains \\
Young-adult3 & 3 months old & 10 brains \\
\hline
\end{tabular}

and Driever, 2007), sox2 for progenitor cells, s100beta for glial cells (März et al., 2010), tmem119 for microglia (Satoh et al., 2016), and neun (rbfox $3 b$ ) for marking post-mitotic neurons (Won et al., 2016). In terms of nestin and neun, the young-adult group had a significantly higher expression $(p=0.0160$ and $p=0.0103$, respectively) when compared to the old group. For sox2 and tmem119, the young-adult group had higher expression when compared to the adult and old groups (sox2: $p=0.085, p=0.0003$; tmem119: $p=0.0231, p=0.0005)$. For $s 100 b e t a$, the expression levels increased numerically during aging, though slightly. Thus, 2 markers of progenitor cells, nestin and sox2, were highly expressed in young-adult, while showing lower expression in older groups despite retaining the expression of these markers. Neurons, glia, and microglia were also represented in our cell culture. Young-adult group had a higher ratio of neurons and microglia, whereas old group was slightly enriched in glia. For all markers, we observed a gradual change during aging. Thus, our cell culture represents brain cells and progenitors for all age groups.

After the quality controls, bioinformatic analysis was performed to identify differentially expressed genes, which are shown in a Venn diagram (Fig. 2A). Here we compared the young-adult to adult and adult to old groups. We did not include a young-adult to old comparison because we wanted to focus on the genes that gradually and consistently change during aging. So we analyzed only the genes that were differentially expressed between old and adult groups, as well as adult and young-adult groups. That being said, we performed a young-adult to old comparison and drew a 3-component Venn diagram (Supplementary Fig. 1), besides drawing the volcano plots to discriminate the genes that were differentially expressed between groups (Supplementary Fig. 2). Between old and adult, 37 genes were differentially expressed, and between adult and youngadult, 153 genes differed in expression. Out of these, 14 genes were common in both lists, and the full list of these genes are given in Supplementary Table 2. In total, 176 genes were found to be significantly different in either comparison. We drew a cluster map out of these 176 genes (Fig. 2B). Looking at the hierarchical clustering of the genes and samples, adult and old were found closer to each other, whereas young-adult profile formed a separate group. Furthermore, we tried to identify whether groups of genes are expressed distinctly in developmental stages. Principal component analysis was performed for the whole data and the groups were separated distinctly as expected (Supplementary Fig. 3). This confirms that the stages of adulthood are distinct from each other in terms of gene expression.

The GO terms were used to describe the cellular component, molecular function, and biological processes of the genes. The GO enrichment chart shows the number of differentially expressed genes associated with specified GO terms. Running our 176 genes in GO analysis, we observed that several GO terms were associated with our genes (Fig. 2C). Likewise, we performed Metascape 
A

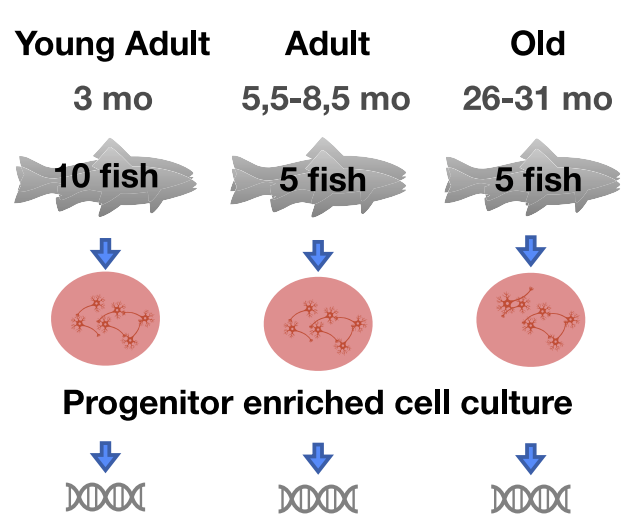

RNA sequencing

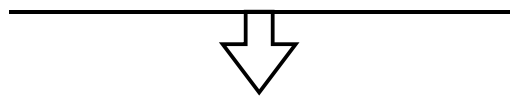

Performed in triplicate
B
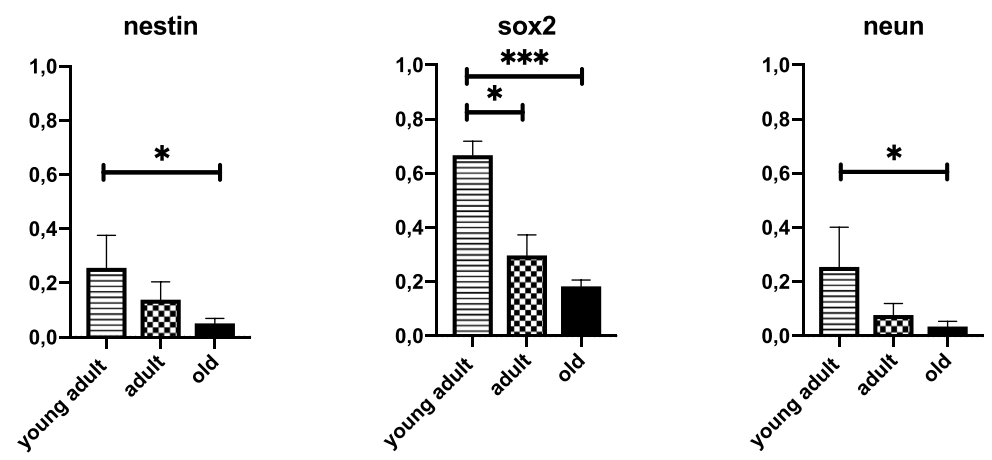

s100b
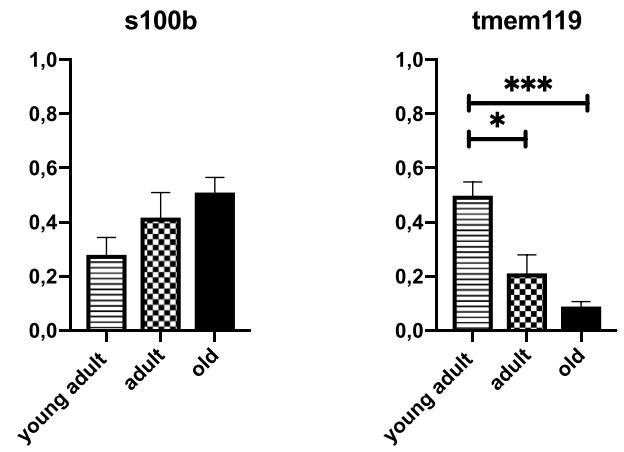

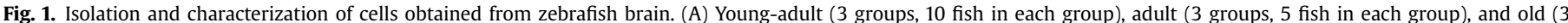

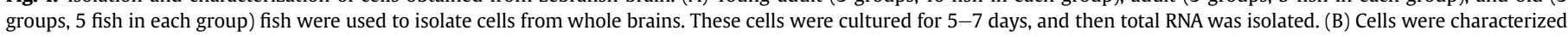

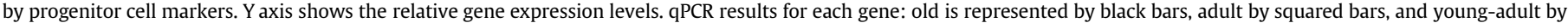
horizontal lines. $n=3$ for each group. ${ }^{*} p<0.05$, ${ }^{* * *} p<0.01$.

analysis to the same gene set (Fig. 2D). Among the profoundly enriched terms there were cell adhesion, biological adhesion, locomotion, axon guidance, and neuron development from biological processes; membrane from the cellular compartment; and receptor binding, cell adhesion molecule binding, and protein binding from molecular function. Cell adhesion and biological adhesion terms were found to be statistically significant. Hence, from the GO analysis, cell adhesion description stands out as an essential pathway altered throughout aging.

\subsection{Functional classification reveals 2 classes of cell adhesion molecules}

Of the 176 significant genes, we aimed at finding the human orthologs. For this purpose, we first ran The database for annotation, visualization, and integrated discovery (DAVID) (Huang et al., 2009a) gene conversion tool to convert the gene IDs; 134 genes were assigned with an Entrez Gene ID (Supplementary Table 3). From this list, 2 comparison lists were created with the fold changes from old to adult, and from adult to young-adult. Here we aimed to find the significant changes through aging. Out of the statistically significant differentially expressed genes (DEG) list, we manually chose genes that are meeting 3 criteria decided as follows: (1) either had a fold change of $<0.5$ or $>2$, (2) changed in the same direction in both comparison lists, and (3) had a gene name, meaning that the transcript is annotated. The final list had 39 genes. of the selected genes, we ran a functional classification in DAVID. This tool is useful in reducing large lists into functional groups so that a related subgroup of genes can be investigated further (Huang et al., 2009b). There, we identified 2 gene groups, which are given in Table 2.
All these genes had human orthologs, except cldnk. Although there were 2 groups, all had a standard description: cell adhesion. Thus, both in this analysis and previously in GO analysis, we found cell adhesion to be a significant class of genes, and therefore decided to focus on these genes.

\subsection{Relative expression levels of cell adhesion molecules in progenitor cell culture and whole zebrafish brains}

In order for verification, different RNA samples were obtained from different sets of fish cohorts from same age groups. Following RNA isolation, qPCR experiments were conducted. For the genes given in Table 2, the qPCR results were as expected. The fold changes were in the same direction for alcam, cldn19, nadl1.2, and mag. For the nfasca, timd4 ( $p=0.04$, between old and young-adult), and $c x 47$ genes, fold changes were in different direction than the RNA sequencing results (Fig. 3).

The results up to now were from progenitor cell culture obtained from pooled zebrafish brains. We also wanted to test the expression of these genes in the individual whole brains via qPCR in order to detect the expression difference or similarity, if any, between the progenitor cells and the whole brains. For this purpose, 7-month and 17-month-old fish were used. The gene expression was significantly changed between 7-month and 17-month old samples, for all genes except nfasca (Fig. 4). Expression of alcam $(p=0.0011)$, cldn19 $(p<0.0001)$, timd4 $(p=0.0003)$, cx47 $(p<0.0001), \operatorname{nadl1}(p$ $<0.0001)$, and mag $(p<0.0001)$ decreased, whereas nfasca increased with age.

Up to this point, we had a differential expression of the cell adhesion genes in different samples. Because it would be possible to have a different expression pattern in whole brain and isolated 


\section{A}
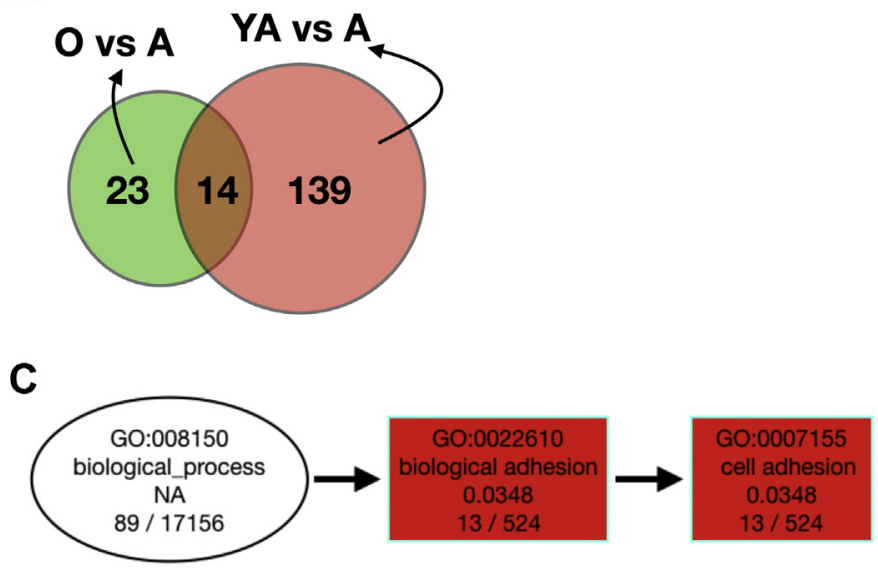

D
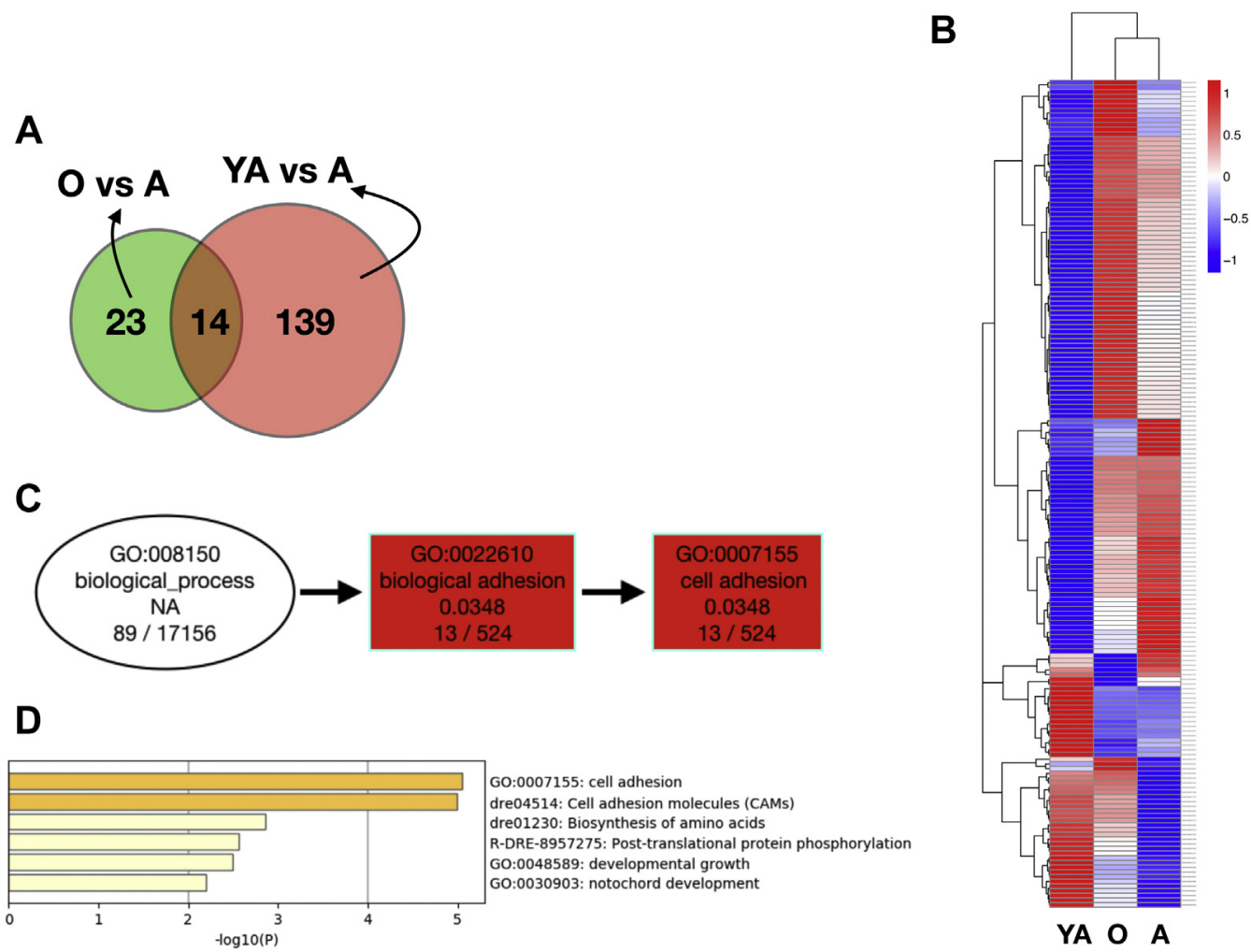

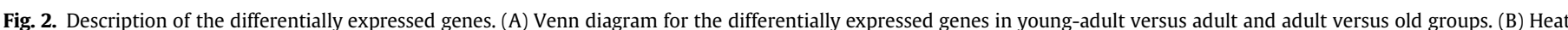

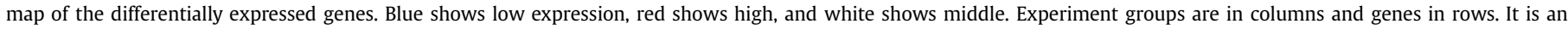

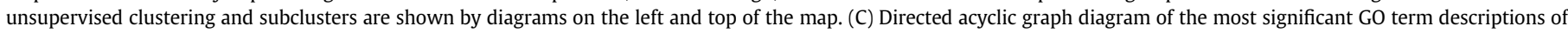

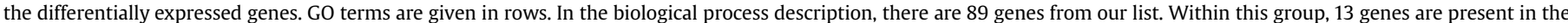

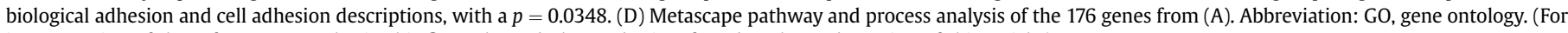
interpretation of the references to color in this figure legend, the reader is referred to the Web version of this article.)

cells for the fact that the cells are a subset of the brain and progenitor cells have a distinct expression, we thought that at this stage it is necessary to test the validity of the expression pattern difference of these genes in the human brain as well.

\subsection{Analysis of the selected genes in healthy and Alzheimer human brain samples}

Therefore as a next step, the expression levels of the selected genes were analyzed in human samples. For that, we ordered human brain RNA samples from Biochain. One RNA sample was indicated by the company to be extracted and pooled from 5 young human male brains, and the other RNA was indicated to be collected from the brain of an Alzheimer's patient of age 87. We first wanted to test the samples for known markers of aging and development. Human telomerase complex has an RNA component called TR, and an enzyme component called TERT. Expression of both TR and TERT genes decline greatly during adulthood; however, they still remain at detectable levels (Spilsbury et al., 2015; Ishaq et al., 2016). In accordance, we observed a deficient but detectable TERT level in our Alzheimer sample RNA (Fig. 5A) $(p=0.0297)$. In the same manner, $T R$ expression was also deficient in the Alzheimer sample ( $p=$ $0.0013)$. For the undifferentiated stem cells, POU Class 5 Homeobox 1 (POU5F1/OCT4) and Nanog homeobox (NANOG) gene expressions are known to be critical for cell proliferation, while Tubulin beta 3 class III (TUBB3, TUJ1) gene is known to be primarily expressed in

Table 2

DAVID gene functional classification result

\begin{tabular}{|c|c|c|}
\hline Ensemble gene ID & Gene name in zebrafish & Gene name in human \\
\hline \multicolumn{3}{|l|}{ Gene group 1} \\
\hline 30634 & Neural adhesion molecule L1.2 (nadl1.2) & L1 cell adhesion molecule (L1CAM) \\
\hline 100141490 & Neurofascin homolog (chicken) a (nfasca) & Neurofascin $(N F A S C)$ \\
\hline 474346 & Myelin associated glycoprotein ( $\mathrm{mag}$ ) & Myelin associated glycoprotein (MAG) \\
\hline 100142639 & T-cell immunoglobulin and mucin domain containing 4 (timd4) & T-cell immunoglobulin and mucin domain containing 4 (TIMD4) \\
\hline 323919 & Activated leukocyte cell adhesion molecule b (alcamb) & Activated leukocyte cell adhesion molecule (ALCAM) \\
\hline \multicolumn{3}{|r|}{ 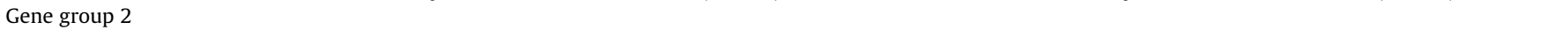 } \\
\hline 445070 & Claudin $\mathrm{k}(\operatorname{cldnk})$ & - \\
\hline 447835 & Connexin $47.1(c x 47.1)$ & Gap junction protein gamma $2(G J C 2)$ \\
\hline 100142639 & T-cell immunoglobulin and mucin domain containing 4 (timd4) & T-cell immunoglobulin and mucin domain containing 4 (TIMD4) \\
\hline 550431 & Claudin 19 (cldn19) & Claudin 19 (CLDN19) \\
\hline
\end{tabular}


alcam

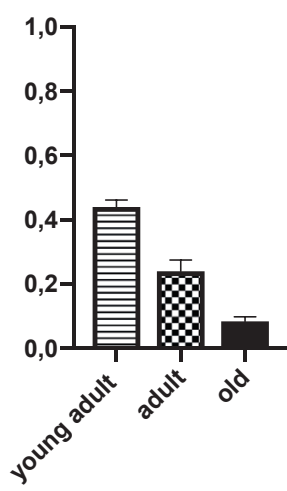

nadl1.2

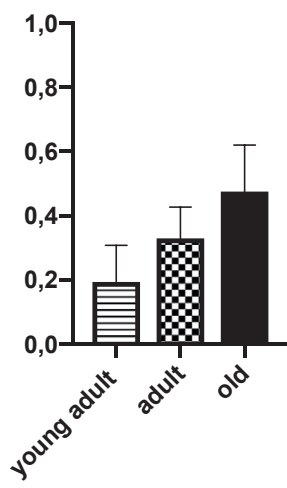

cldn19

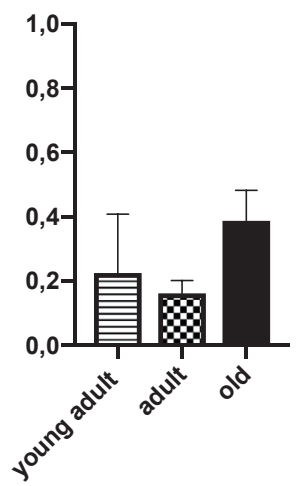

mag

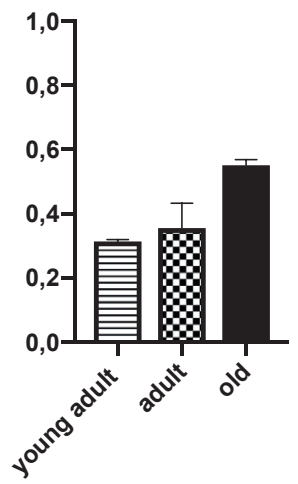

timd4

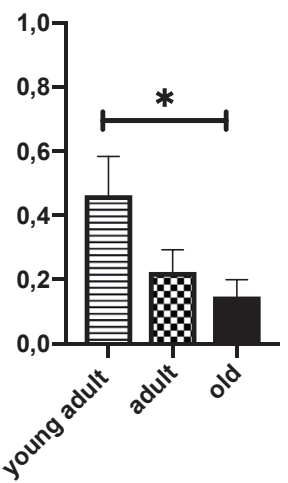

nfasca

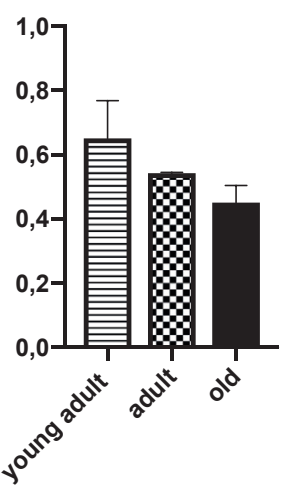

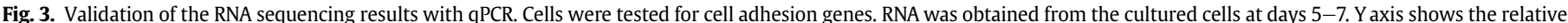

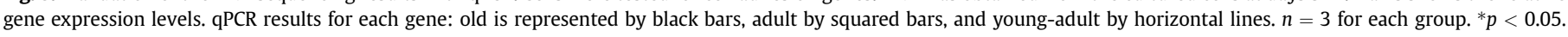

neurons. For these 3 genes, we ran qPCR for healthy and Alzheimer samples and saw that all 3 reduced in Alzheimer samples in substantial amounts (Fig. 5A). For DNMT1 $(p=0.012)$, OCT4 $(p=$ $0.0344)$, NANOG $(p=0.06)$, and TUJ1 $(p=0.001)$, the expressions were lower in Alzheimer sample compared to the healthy sample. Then, we analyzed the genes that we chose from the RNA sequencing data. We found that each of these genes were decreased in Alzheimer samples, except TIMD4, which had similar levels in both samples. The decreases in expression levels of ALCAM $(p<0.0001)$, CLDN19 ( $p=0.008)$, L1CAM $(p<0.0001)$, MAG $(p=0.0006)$, and NFASC $(p=0.0002)$ in Alzheimer sample were statistically significant (Fig. 5B).

In order to examine the interaction of these proteins with each other and with some aging-related proteins, we used Cytoscape software (Supplementary Fig. 4), in which L1CAM and ALCAM were identified to interact with each other, while MAG and GJC2 formed another separate interaction together. Furthermore, ALCAM was also found to be interacting with NANOG, OCT4, and SOX2 directly, and with TERT and DNMT1 indirectly.

\subsection{Expression data of the selected genes in Allen Brain Atlas dataset}

Finally, we wanted to see the expression profile of the selected genes in existing RNA sequencing data. From the Allen Brain Atlas study, "Aging, Dementia, and TBI" database, we analyzed the distribution of our selected genes. First, we did a cluster analysis according to increasing age. Here we could not see any grouping (data not shown). We assumed that the reason for obtaining no grouping in the data was that the youngest person included in this database was 78 years old. So our analysis was actually a clustering analysis of old versus very old. However, very interestingly, when we clustered our selected genes according to brain regions, we noticed a remarkable grouping. Our selected genes were highly expressed in the frontal white matter, which is a brain region of particular importance in aging. So as seen in Fig. 6, in the old human brain, NFASC, ALCAM, DLG1, and MAG genes were highly expressed in the frontal white matter when compared to other brain regions that were studied here. Moreover, L1CAM gene was highly expressed in the parietal and temporal cortex when compared to the hippocampus and frontal white matter. Although we could not infer the age differences in this data, in the old brain, the gene expression patterns seem to vary greatly among the brain regions.

For a better comprehension, our results are gathered in a figure complemented with a visual presentation (Fig. 7). Fig. 7A demonstrates the positions of the cell adhesion proteins and possible interactions, while Fig. 7B summarizes our findings in this study in a table view. In the figure, ALCAM proteins are presented in the membranes of antigen presenting cells pairing with CD6 proteins residing on T cells (Fig. 7A, label 1), L1CAM is shown forming homodimers through pre- and post-synaptic neurons (Fig. 7A, label 2), CLDN (CLDN19 and CLDN16) is demonstrated forming junctions in endothelial cells (Fig. 7A, label 3), MAG is represented in myelinproducing Schwann cells, and NFASC is in myelin-producing cells interacting with CNTN1 protein in axons (Fig. 7A, label 4), and finally GJC2 (also known as CX47) is drawn in oligodendrocytes either forming homodimers in oligodendrocytes or heterodimers with a CX43 protein residing in an astrocyte (Fig. 7A, label 5). Our 

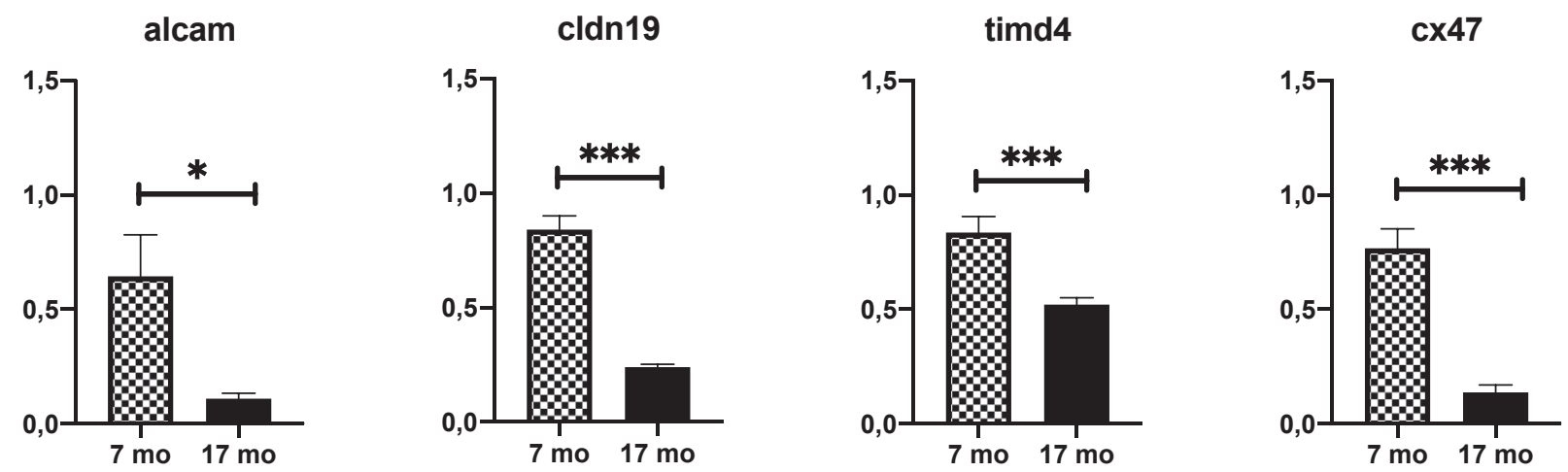

nadl1

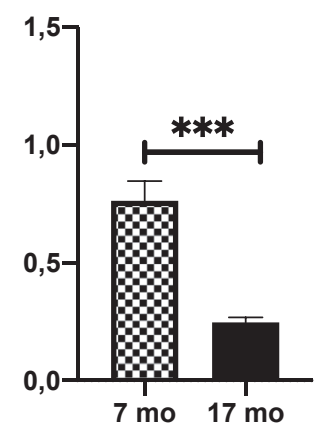

mag

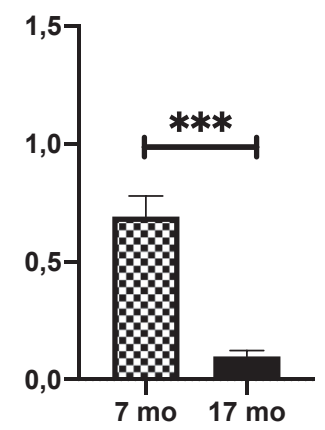

nfasca

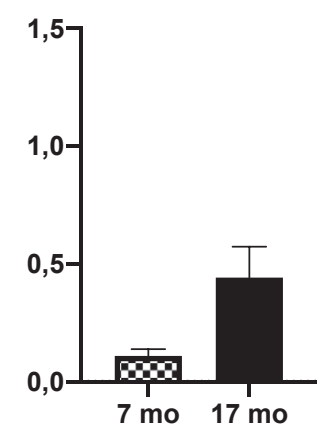

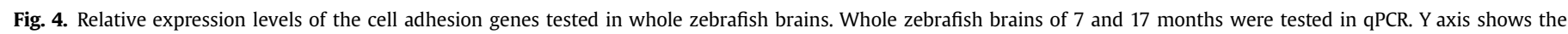
relative gene expression levels. Seven months is represented by squared bars and 17 months by black bars. $n=3$ for each group. ${ }^{*} p<0.05$, ${ }^{* * *} p<0.001$.

results showed that $A L C A M$ and GJC2 are consistently decreasing with age in all of our analysis, while CLDN19, L1CAM, MAG, and NFASC establish a decreasing expression pattern in 2 out of 4 experiments, and increasing in others.

\section{Discussion}

In this study, we investigated the age-related gene expression level differences of a group of cell adhesion molecules. We tested the genes in zebrafish brain derived progenitor-enriched cells via RNA sequencing and qPCR, as well as in whole zebrafish brain and commercially available human brain samples via qPCR. Our results showed that the cell adhesion molecules, especially the ones we included in this study, play critical roles in aging. Among all mentioned genes, the decreasing pattern of expression of alcamb/ ALCAM and $c x 47 / G J C 2$ with age remarkably showed consistency in all our data, which highlights a prospective target for age-related neurodegenerative diseases opening the doors for new therapeutic strategies and drug targets for the age-related deterioration. Although some of these genes were well-studied and some are not, there are not enough studies on literature searching answers related to their roles in aging, or therapeutical options targeting these genes. This makes our study an interesting one letting us observe their functional roles with age.

In this study, we identified several cell adhesion protein genes that show altered expression in aging. Below we briefly summarized the literature regarding the most profound ones: ALCAM, GJC2, L1CAM, CLDN19, MAG, NFASC, and TIMD4.

ALCAM (also known as CD166) is a member of the type I transmembrane immunoglobulin superfamily of cell adhesion molecules, sharing 93\% similarity between human and mouse orthologs (Bowen et al., 1997). The name stands for activated leukocyte cell adhesion molecule (ALCAM), mainly because it is expressed in the surface of activated leukocytes (Bowen et al., 1995), being involved in leukocyte migration through blood-brain barrier (BBB) tight junctions and having roles in synaptic transmission modulation (Cayrol et al., 2008; Curis et al., 2016; Lécuyer et al., 2017; Park et al., 2017). On leukocytes it acts by attracting and recruiting leukocytes into the inflammation site (Shahaduzzaman et al., 2015). Cayrol et al. (2008) stated that blocking ALCAM reduced neuroinflammation via promoting leukocyte recruitment to the central nervous system. In addition to leukocytes, ALCAM is widely expressed in various cells, including neurons, epithelial cells, fibroblasts, lymphoid cells, myeloid cells, as well as being an accepted cell surface marker of mesenchymal and hematopoietic progenitor cells (Yasen, 2013; Shahaduzzaman et al., 2015). With the upregulation of $A L C A M$, migration and adhesion were observed to be increased in synovial fluid-derived mesenchymal stem cells (Kim et al., 2017). And in like manner, Alcam-null (Alcam-/-) mouse model hematopoietic stem cells were demonstrated to be associated with reduced long-term engraftment potential following transplantation, having no effect on cell cycle distribution regardless of age (Jeannet et al., 2014). In the study, Alcam expression was also claimed to be increased by several fold in aged murine hematopoietic stem cells compared to young ones. In relation to cancer, being in accordance with the fact that natural ligands to cell adhesion molecules were shown to be highly expressed in metastatic tumor cells, antibody neutralization of ALCAM (antibody blocking specific tumor-expressed ligands) reduced the tumor seeding in the brain (Soto et al., 2014). From these aspects, increased ALCAM expression levels seem to be correlated with cancerous and inflammatory phenotypes in some cell types while 

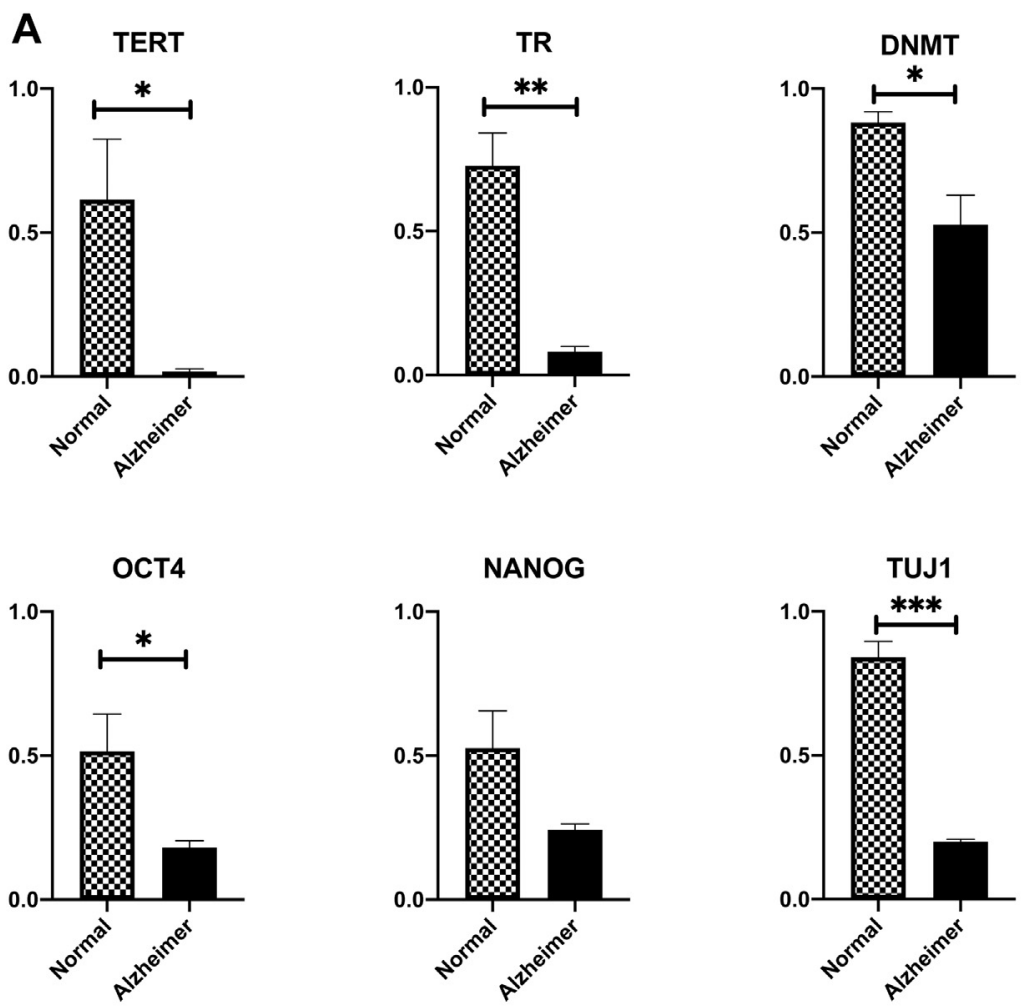

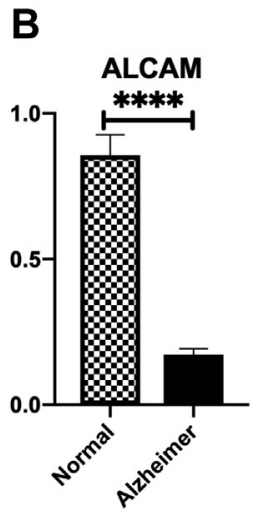

CLDN19
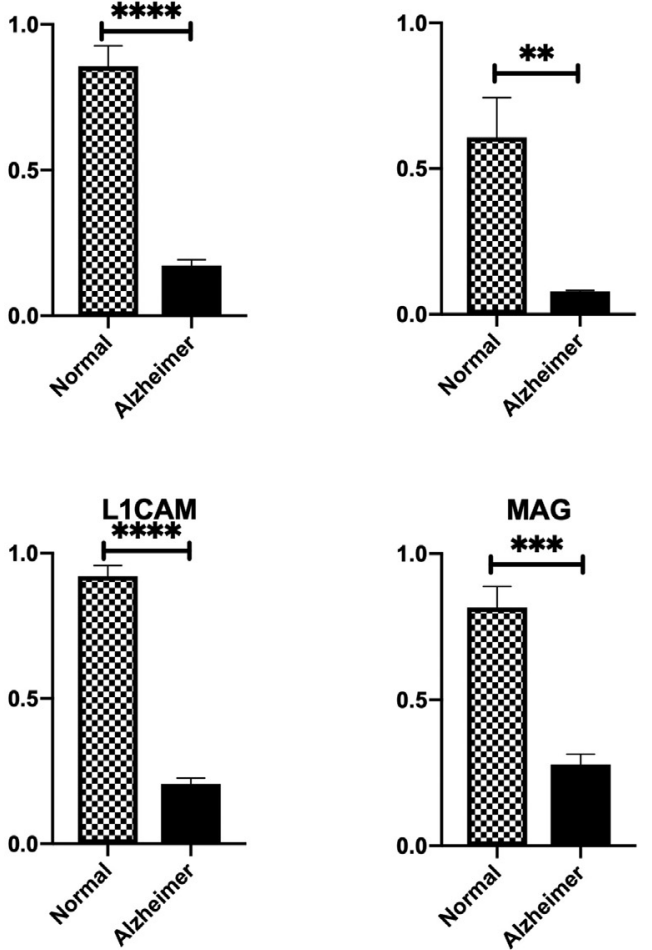

GJC2
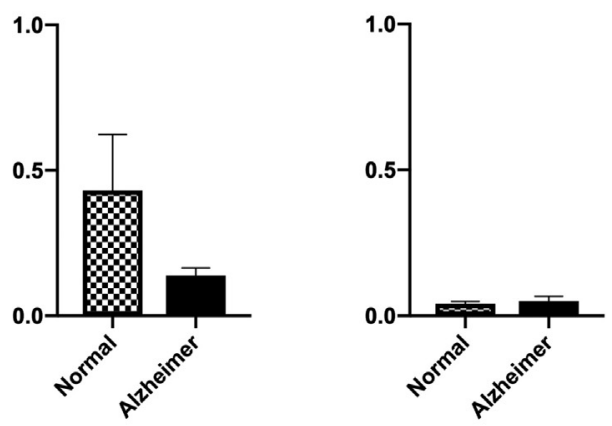

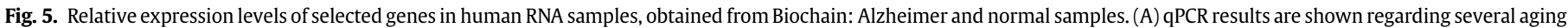

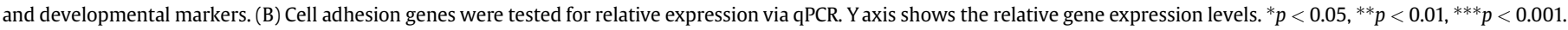

being associated somehow with stem cell ability, which makes its fine-tuning important for the proper functioning of the cells. Considering the research literature gap for ALCAM age-related alterations in the brain, testing the gene expression change with age is thought to have crucial contributions to our understanding of the age-related increased susceptibility for neurodegenerative diseases, as an addition to its known roles in metastasis and trafficking through BBB. Moreover, since it has known effects on 


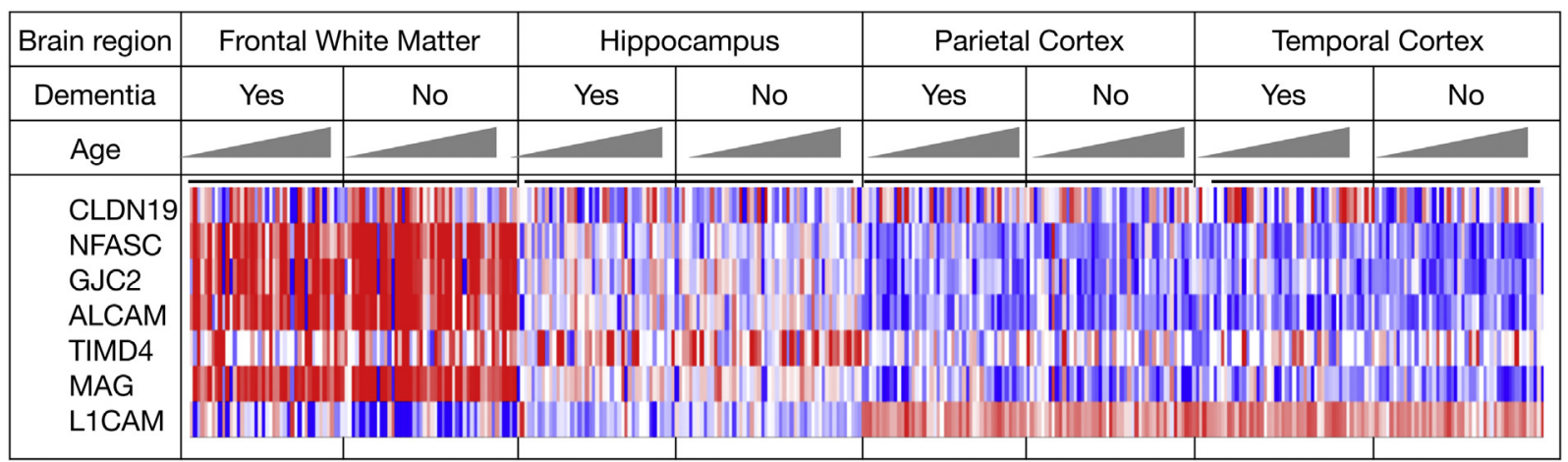

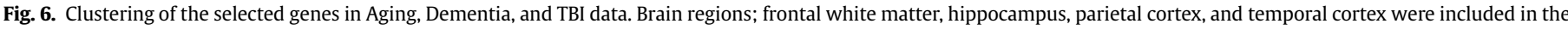

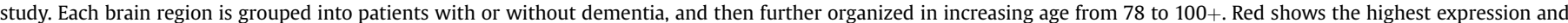

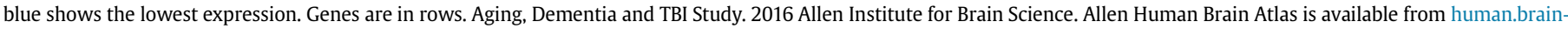

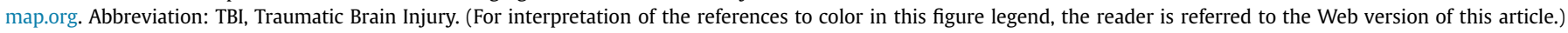

neuroinflammation, it is possible to think of a relation between ALCAM gene expression and AD.

GJC2 gene is expressed in oligodendrocytes, and the protein is crucial for gap junctional communication (Georgiou et al., 2017). A mutation in GJC2, leading to the loss of connexin 47 protein, was implicated in hypomyelinating leukodystrophy-2 disease (Pelizaeus-Merzbacher-like disease), which in its severe forms results in hypomyelination (Al-Yahyaee et al., 2013), and in hereditary spastic paraplegia (Abrams, 2019). Therefore mutations occurring in GJC2 gene have severe consequences. Though, to our knowledge there is no study investigating how GJC2 is affected in the brain through aging and AD progression. Having a function in myelination, we think that the gene could have a vital role in both aging and AD.

Immunoglobulin-like cell adhesion molecule (L1CAM), also known as CD171, has a dual function in cells: one being as a static cell adhesion molecule and the other as a motility promoting molecule, which has functions during neural development and metastasis (Kiefel et al., 2012). Similarly, the integrin family of receptor and cell adhesion proteins provide communication between cell to cell as well as cell to extracellular matrix, besides being known to correlate with cancer incidence and metastasis. The ability of L1CAM binding to integrins was suggested to be associated with its promigratory and proinvasive effects in cancer cells (Burgett et al., 2016; Nieberler, 2017). In another study, a zebrafish knockout model of nadl1.2 (L1CAM zebrafish ortholog; Table 2) was indicated having problems in axonal growth, and also myelination abnormalities (Linneberg et al., 2019). Furthermore, as suggested by Shi et al. (2016), tau proteins reside explicitly within L1CAM expressing exosomes in human plasma, via which toxic tau aggregates are transported from cell to cell contributing to the formation of tauopathies according to a hypothesis. To mention its relation to senescence, L1CAM is stated to be enriched on the surface of senescent fibroblasts and aid their migration (Mrazkova et al., 2018).
A

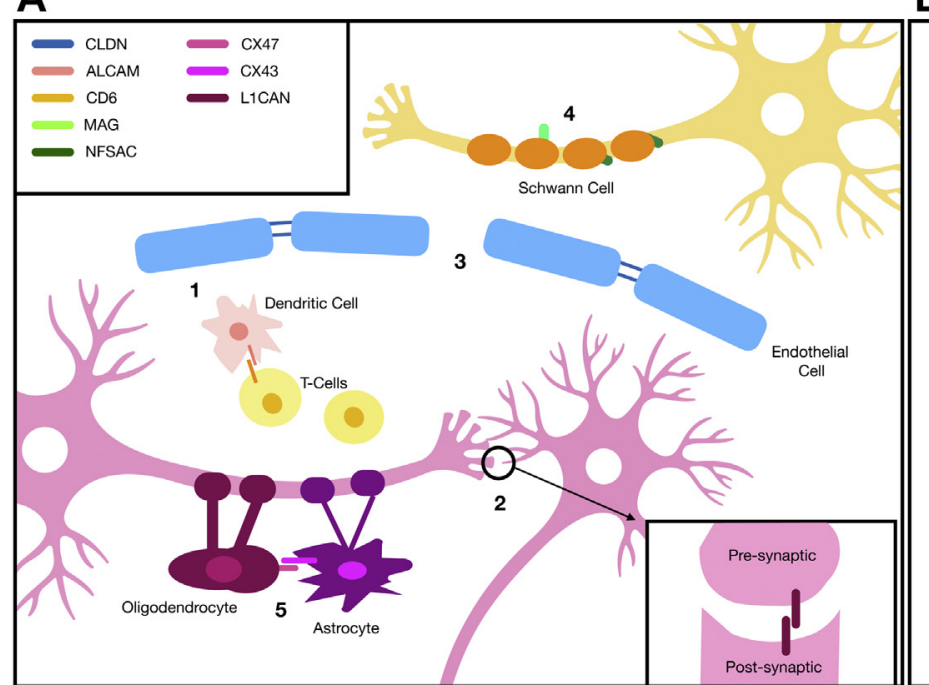

B

\begin{tabular}{|c|c|c|c|c|c|}
\hline $\begin{array}{c}\text { Gene } \\
\text { name: } \\
\text { (zebrafish) }\end{array}$ & $\begin{array}{l}\text { RNA seq: } \\
\text { cell } \\
\text { culture }\end{array}$ & $\begin{array}{l}\text { qPCR: } \\
\text { cell } \\
\text { culture }\end{array}$ & $\begin{array}{l}\text { qPCR: } \\
\text { whole } \\
\text { brain }\end{array}$ & $\begin{array}{c}\text { qPCR: } \\
\text { human } \\
\text { brain }\end{array}$ & $\begin{array}{c}\text { Gene } \\
\text { name: } \\
\text { (human) }\end{array}$ \\
\hline alcamb & & & & & ALCAM \\
\hline cldn19 & & & & & CLDN19 \\
\hline$c \times 47$ & & & & & GJC2 \\
\hline nadl1.2 & & & & & L1CAM \\
\hline mag & & & & & MAG \\
\hline nfasca & & & & & NFASC \\
\hline timd4 & & & & & TIMD4 \\
\hline
\end{tabular}

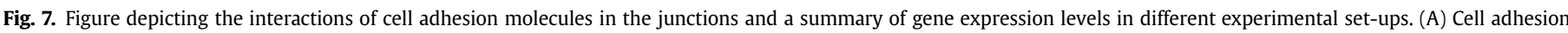

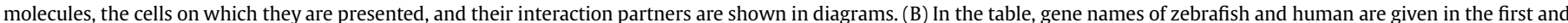

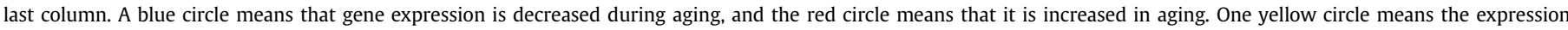

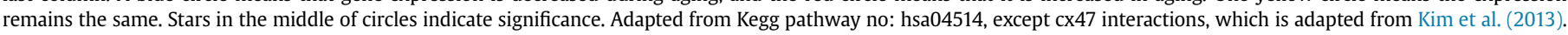

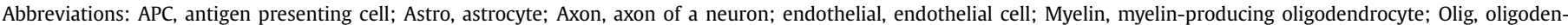

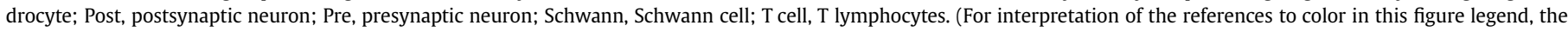
reader is referred to the Web version of this article.) 
Another cell adhesion molecule, CLDN19, encodes a tight junction protein (Perdomo-Ramirez et al., 2019). Together with CLDN16, it forms a permeable channel for magnesium and calcium ions (Giménez-Mascarell et al., 2018). Mutations of CLDN19 were shown to disrupt retinal neurogenesis (Wang et al., 2019), leading to hypomagnesemia, hypercalciuria, and ocular abnormalities (Perdomo-Ramirez et al., 2019; Vall-Palomar et al., 2018). Thus, whether this gene has a role in neurogenesis through aging is intriguing to follow. The fact that CLDN19 is expressed in endothelial cells forming a magnesium channel, suggests a role in aging by again regulating the BBB traffic.

MAG is a type I transmembrane glycoprotein being expressed in myelinating oligodendrocytes and Schwann cells (Pronker et al., 2016). It takes part in myelin maintenance, as in GJC2, and survival of oligodendrocytes (Quarles, 2007). Mutations in this gene cause the same Pelizaeus-Merzbacher-like disease as in the case of GJC2 gene mutations with ill-formed onion bulb structures and thin myelin sheath of the affected axons (Lossos et al., 2015). In like manner, mice deficient in MAG have defects in the formation and maintenance of myelin and possibly in axonal function (Bartsch et al., 1996; Kamil et al., 2019).

Besides above-mentioned ones, neurofascin cell adhesion proteins take part in the node of Ranvier assembling the nodal macromolecular complex which includes the voltage-gated sodium channels (Zhang et al., 2015). They also have roles in the maintenance of the node and myelinated axon function (Ebel et al., 2014; Taylor et al., 2017), in addition to providing a permissive environment for neurite extension together with N1CAM (Volkmer et al., 1996). Therefore consistently, antibodies to neurofascin isoforms result in inflammatory demyelinating neuropathy and multifocal motor neuropathy (Delmont et al., 2017; Devaux et al., 2016; Notturno et al., 2014). Last but not the least, being another cell adhesion protein, TIMD4 is a type I membrane protein known to regulate $\mathrm{TH} 1$ and $\mathrm{TH} 2$ cell response (Yano et al., 2017). It contains an arginine-glycine-aspartate tripeptide (RGD domain), which indicates a role in cell adhesion.

Our study had several weaknesses though. First, we could not find commercially available healthy brain sample collected from an old age human individual. Therefore, although we wanted to compare the healthy old aged human sample with the old aged Alzheimer sample, and healthy old aged human sample with young aged one, due to ethical constraints we could not be able to perform such tests. Second, in Allen Brain Atlas, the ages were again advanced, ranging from 78 to $100+$. So again in this data we could only be able to work with the old age group. Nevertheless, by combining data from different sources, we tried to deduct meaningful results.

This study provides evidence that the gene expression levels of a group of cell adhesion molecules change during aging and with AD. Therefore, the findings suggest a prominent role for these molecules during brain aging, besides having a potential for them to take part in future studies on aging and neurodegenerative diseases.

\section{Disclosure statement}

The authors report no conflicts of interest.

\section{CRediT authorship contribution statement}

Begün Erbaba: Conceptualization, Methodology, Investigation, Writing - review \& editing. Özge Pelin Burhan: Conceptualization, Methodology, Formal analysis, Investigation, Data curation, Visualization. Naz Şerifoğlu: Methodology, Investigation, Visualization. Bihter Muratoglu: Validation. Fatma Kahveci: Software, Formal analysis. Michelle M. Adams: Resources, Project administration.
Ayça Arslan-Erguil: Conceptualization, Methodology, Resources, Data curation, Writing - original draft, Writing - review \& editing, Supervision, Project administration, Funding acquisition.

\section{Acknowledgements}

This work was supported by The Scientific and Technological Research Council of Turkey (TUBITAK) (project no: 114S548) and Science Academy's Young Scientist Awards Program (BAGEP). The authors thank Aydan Saraç from TUBiTAK-MAM and Tülay Arayıcı from BilGen Zebrafish Lab for their help in our experiments.

\section{Appendix A. Supplementary data}

Supplementary data associated with this article can be found, in the online version, at https://doi.org/10.1016/j.neurobiolaging. 2020.04.017.

\section{References}

Abrams, C.K., 2019. Diseases of connexins expressed in myelinating glia. Neurosci. Lett. 695, 91-99.

Adusumalli, S., Ngian, Z.K., Lin, W.Q., Benoukraf, T., Ong, C.T., 2019. Increased intron retention is a post-transcriptional signature associated with progressive aging and Alzheimer's disease. Aging Cell 18, e12928.

Al-Yahyaee, S.A., Al-Kindi, M., Jonghe, P.D., Al-Asmi, A., Al-Futaisi, A., Vriendt, E.D. Deconinck, T., Chand, P., 2013. Pelizaeus-Merzbacher-like disease in a family with variable phenotype and a novel splicing GJC2 mutation. J. Child Neurol. 28 $1467-1473$.

Arslan-Ergul, A., Adams, M.M., 2014. Gene expression changes in aging zebrafish (Danio rerio) brains are sexually dimorphic. BMC Neurosci. 15, 29.

Arslan-Ergul, A., Erbaba, B., Karoglu, E.T., Halim, D.O., Adams, M.M., 2016. Shortterm dietary restriction in old zebrafish changes cell senescence mechanisms. Neuroscience 334, 64-75.

Ashburner, M., Ball, C.A., Blake, J.A., Botstein, D., Butler, H., Cherry, J.M., Davis, A.P., Dolinski, K., Dwight, S.S., Eppig, J.T. Harris, M.A., Hill, D.P., Issel-Tarver, L. Kasarskis, A., Lewis, S., Matese, J.C., Richardson, J.E., Ringwald, M., Rubin, G.M., Sherlock, G., 2000. Gene ontology: tool for the unification of biology. The Gene Ontology Consortium. Nat. Genet. 25, 25-29.

Bae, S.H., Kim, H.W., Shin, S., Kim, J., Jeong, Y.H., Moon, J., 2018. Decipher reliable biomarkers of brain aging by integrating literature-based evidence with interactome data. Exp. Mol. Med. 50, 28.

Bao, X., Liu, G., Jiang, Y., Jiang, Q., Liao, M., Feng, R, Zhang, L, Ma, G., Zhang, S. Chen, Z., Zhao, B., Wang, R., Li, K., Liu, G., 2015. Cell adhesion molecule pathway genes are regulated by cis-regulatory SNPs and show significantly altered expression in Alzheimer's disease brains. Neurobiol. Aging 36, 2904.e1-2904.e7.

Bartsch, U., 1996. Myelination and axonal regeneration in the central nervous system of mice deficient in the myelin-associated glycoprotein. J. Neurocytol. 25 303-313.

Bowen, M.A., Bajorath, J., D'Egidio, M., Whitney, G.S., Palmer, D., Kobarg, J., Starling, G.C., Siadak, A.W., Aruffo, A., 1997. Characterization of mouse ALCAM (CD166): the CD6-binding domain is conserved in different homologs and mediates cross-species binding. Eur. J. Immunol. 27, 1469-1478.

Bowen, M.A., Patel, D.D., Li, X., Modrell, B., Malacko, A.R., Wang, W.C., Marquardt, H., Neubauer, M., Pesando, J.M., Francke, U., Haynes, B.F., Aruffo, A., 1995. Cloning, mapping, and characterization of activated leukocyte-cell adhesion molecule (ALCAM), a CD6 ligand. J. Exp. Med. 181, 2213-2220.

Burgett, M.E., Lathia, J.D., Roth, P., Nowacki, A.S., Galileo, D.S., Pugacheva, E., Huang, P., Vasanji, A., Li, M., Byzova, T., Mikkelsen, T., Bao, S., Rich, J.N. Weller, M., Gladson, C.L., 2016. Direct contact with perivascular tumor cells enhances integrin $\alpha v \beta 3$ signaling and migration of endothelial cells. Oncotarget 7, 43852-43867.

Cayrol, R., Wosik, K. Berard, J.L., Dodelet-Devillers, A., Ifergan, I., Kebir, H. Haqqani, A.S., Kreymborg, K., Krug, S., Moumdjian, R., Bouthillier, A., Becher, B. Arbour, N., David, S., Stanimirovic, D., Prat, A., 2008. Activated leukocyte cell adhesion molecule promotes leukocyte trafficking into the central nervous system. Nat. Immunol. 9, 137-145.

Curis, C., Percher, F., Jeannin, P., Montange, T., Chevalier, S.A., Seilhean, D., Cartier, L. Couraud, P.O., Gout, O., Gessain, A., Ceccaldi, P.E., Afonso, P.V., 2016. Human Tlymphotropic virus type 1-induced overexpression of activated leukocyte cell adhesion molecule (ALCAM) facilitates trafficking of infected lymphocytes through the blood-brain barrier. J. Virol. 90, 7303-7312.

Delmont, E., Manso, C., Querol, L., Cortese, A., Berardinelli, A., Lozza, A., Belghazi, M. Malissart, P., Labauge, P., Taieb, G., Yuki, N., Illa, I., Attarian, S., Devaux, J.J., 2017. Autoantibodies to nodal isoforms of neurofascin in chronic inflammatory demyelinating polyneuropathy. Brain 140, 1851-1858. 
Devaux, J.J., Miura, Y., Fukami, Y., Inoue, T., Manso, C., Belghazi, M., Sekiguchi, K., Kokubun, N., Ichikawa, H., Wong, A.H., Yuki, N., 2016. Neurofascin-155 IgG4 in chronic inflammatory demyelinating polyneuropathy. Neurology 86, 800-807.

Dönertaş, H.M., İzgi, H., Kamacıoğlu, A., He, Z., Khaitovich, P., Somel, M., 2017. Gene expression reversal toward pre-adult levels in the aging human brain and agerelated loss of cellular identity. Sci. Rep. 7, 5894.

Ebel, J., Beuter, S., Wuchter, J., Kriebel, M., Volkmer, H., 2014. Organisation and control of neuronal connectivity and myelination by cell adhesion molecule neurofascin. Adv. Neurobiol. 8, 231-247.

Frahm, C., Srivastava, A., Schmidt, S., Mueller, J., Groth, M., Guenther, M., Ji, Y., Priebe, S., Platzer, M., Witte, O.W., 2017. Transcriptional profiling reveals protective mechanisms in brains of long-lived mice. Neurobiol. Aging 52, 23-31.

Georgiou, E., Sidiropoulou, K., Richter, J., Papaneophytou, C., Sargiannidou, I., Kagiava, A., von Jonquieres, G., Christodoulou, C., Klugmann, M., Kleopa, K.A., 2017. Gene therapy targeting oligodendrocytes provides therapeutic benefit in a leukodystrophy model. Brain 140, 599-616.

Giménez-Mascarell, P., Schirrmacher, C.E., Martínez-Cruz, L.A., Müller, D., 2018. Novel aspects of renal magnesium homeostasis. Front. Pediatr. 6, 77.

Howe, K., Clark, M.D., Torroja, C.F., Torrance, J., Berthelot, C., Muffato, M., Stemple, D.L., 2013. The zebrafish reference genome sequence and its relationship to the human genome. Nature 496, 498-503.

Huang, da W., Sherman, B.T., Lempicki, R.A., 2009a. Bioinformatics enrichment tools: paths toward the comprehensive functional analysis of large gene lists. Nucleic Acids Res. 37, 1-13.

Huang, da W., Sherman, B.T., Lempicki, R.A., 2009b. Systematic and integrative analysis of large gene lists using DAVID bioinformatics resources. Nat. Protoc. 4 , 44-57.

Ianov, L., De Both, M., Chawla, M.K., Rani, A., Kennedy, A.J., Piras, I., Day, J.J., Siniard, A., Kumar, A., Sweatt, J.D., Barnes, C.A., Huentelman, M.J., Foster, T.C., 2017. Hippocampal transcriptomic profiles: subfield vulnerability to age and cognitive impairment. Front. Aging Neurosci. 9, 383.

Ishaq, A., Hanson, P.S., Morris, C.M., Saretzki, G., 2016. Telomerase activity is downregulated early during human brain development. Genes (Basel) 7. https:// doi.org/10.3390/genes7060027.

Jeannet, R., Cai, Q., Liu, H., Vu, H., Kuo, Y.H., 2013. Alcam regulates long-term hematopoietic stem cell engraftment and self-renewal. Stem Cells 31, 560-571.

Kamil, K., Yazid, M.D., Idrus, R.B.H., Das, S., Kumar, J., 2019. Peripheral demyelinating diseases: from biology to translational medicine. Front. Neurol. 10, 87.

Karoglu, E.T., Halim, D.O., Erkaya, B., Altaytas, F., Arslan-Ergul, A., Konu, O., Adams, M.M., 2017. Aging alters the molecular dynamics of synapses in a sexually dimorphic pattern in zebrafish (Danio rerio). Neurobiol. Aging 54, $10-21$.

Kedlian, V.R., Donertas, H.M., Thornton, J.M., 2019. The widespread increase in interindividual variability of gene expression in the human brain with age. Aging (Albany NY) 11, 2253-2280. https://doi.org/10.18632/aging.101912.

Kennerdell, J.R., Liu, N., Bonini, N.M., 2018. MiR-34 inhibits polycomb repressive complex 2 to modulate chaperone expression and promote healthy brain aging. Nat. Commun. 9, 4188.

Kiefel, H., Bondong, S., Hazin, J., Ridinger, J., Schirmer, U., Riedle, S., Altevogt, P., 2012. L1CAM: a major driver for tumor cell invasion and motility. Cell Adh Migr 6, $374-384$.

Kim, M.S., Gloor, G.B., Bai, D., 2013. The distribution and functional properties of Pelizaeus-Merzbacher-like disease-linked Cx47 mutations on Cx47/Cx47 homotypic and Cx47/Cx43 heterotypic gap junctions. Biochem. J. 452, 249-258.

Kim, R., Park, S.I., Lee, C.Y., Lee, J., Kim, P., Oh, S., Lee, H., Lee, M.Y., Kim, J., Chung, Y.A., Hwang, K.C., Maeng, L.S., Chang, W., 2017. Alternative new mesenchymal stem cell source exerts tumor tropism through ALCAM and N-cadherin via regulation of microRNA-192 and -218. Mol. Cell Biochem. 427, 177-185.

Kishi, S., 2014. Using zebrafish models to explore genetic and epigenetic impacts on evolutionary developmental origins of aging. Transl. Res. 163, 123-135.

Kizil, C., 2018. Mechanisms of pathology-induced neural stem cell plasticity and neural regeneration in adult zebrafish brain. Curr. Pathobiol. Rep. 6, 71-77.

Lécuyer, M.A., Saint-Laurent, O., Bourbonnière, L., Larouche, S., Larochelle, C., Michel, L., Charabati, M., Abadier, M., Zandee, S., Haghayegh Jahromi, N., Gowing, E., Pittet, C., Lyck, R., Engelhardt, B., Prat, A., 2017. Dual role of ALCAM in neuroinflammation and blood-brain barrier homeostasis. Proc. Natl. Acad. Sci. U. S A. 114, E524-E533.

Li, Z., Bammann, H., Li, M., Liang, H., Yan, Z., Phoebe Chen, Y.P., Zhao, M., Khaitovich, P., 2013. Evolutionary and ontogenetic changes in RNA editing in human, chimpanzee, and macaque brains. RNA 19, 1693-1702.

Linneberg, C., Toft, C.L.F., Kjaer-Sorensen, K., Laursen, L.S., 2019. L1cam-mediated developmental processes of the nervous system are differentially regulated by proteolytic processing. Sci. Rep. 9, 3716.

Liu, G., Jiang, Y., Wang, P., Feng, R., Jiang, N., Chen, X., Song, H., Chen, Z., 2012. Cell adhesion molecules contribute to Alzheimer's disease: multiple pathway analyses of two genome-wide association studies. J. Neurochem. 120, 190-198.

Lossos, A., Elazar, N., Lerer, I., Schueler-Furman, O., Fellig, Y., Glick, B., Zimmerman, B.E., Azulay, H., Dotan, S., Goldberg, S., Gomori, J.M., Ponger, P., Newman, J.P., Marreed, H., Steck, A.J., Schaeren-Wiemers, N., Mor, N., Harel, M., Geiger, T., Eshed-Eisenbach, Y., Meiner, V., Peles, E., 2015. Myelin-associated glycoprotein gene mutation causes Pelizaeus-Merzbacher disease-like disorder. Brain 138 (Pt 9), 2521-2536.

Mahler, J., Driever, W., 2007. Expression of the zebrafish intermediate neurofilament Nestin in the developing nervous system and in neural proliferation zones at postembryonic stages. BMC Dev. Biol. 7, 89.
März, M., Chapouton, P., Diotel, N., Vaillant, C., Hesl, B., Takamiya, M., Lam, C.S. Kah, O., Bally-Cuif, L., Strähle, U., 2010. Heterogeneity in progenitor cell subtypes in the ventricular zone of the zebrafish adult telencephalon. Glia 58, 870-888.

Mazin, P., Xiong, J., Liu, X., Yan, Z., Zhang, X., Li, M., He, L., Somel, M., Yuan, Y., Phoebe Chen, Y.P., Li, N., Hu, Y., Fu, N., Ning, Z., Zeng, R., Yang, H., Chen, W., Gelfand, M., Khaitovich, P., 2013. Widespread splicing changes in human brain development and aging. Mol. Syst. Biol. 9, 633.

Mrazkova, B., Dzijak, R., Imrichova, T., Kyjacova, L., Barath, P., Dzubak, P., Holub, D., Hajduch, M. Nahacka, Z., Andera, L., Holicek, P., Vasicova, P., Sapega, O., Bartek, J., Hodny, Z., 2018. Induction, regulation and roles of neural adhesion molecule L1CAM in cellular senescence. Aging (Albany NY) 10, 434-462.

Nieberler, M., Reuning, U., Reichart, F., Notni, J., Wester, H.J., Schwaiger, M., Weinmüller, M., Räder, A., Steiger, K., Kessler, H., 2017. Exploring the role of RGD-recognizing integrins in cancer. Cancers 9, 116.

Notturno, F., Di Febo, T., Yuki, N., Fernandez Rodriguez, B.M., Corti, D., NobileOrazio, E., Carpo, M., De Lauretis, A., Uncini, A., 2014. Autoantibodies to neurofascin-186 and gliomedin in multifocal motor neuropathy. J. Neuroimmunol. 276, 207-212.

Papadimitriou, C., Celikkaya, H., Cosacak, M.I., Mashkaryan, V., Bray, L., Bhattarai, P. Brandt, K., Hollak, H., Chen, X., He, S., Antos, C.L., 2018. 3D culture method for Alzheimer's disease modeling reveals interleukin-4 rescues A $\beta 42$-induced loss of human neural stem cell plasticity. Dev. Cel. 46, 85-101.

Park, E.S., Jeon, S.M., Weon, H., Cho, H.J., Youn, D.H., 2017. Activated leukocyte cell adhesion molecule is involved in excitatory synaptic transmission and plasticity in the rat spinal dorsal horn. Neurosci. Lett. 656, 9-14.

Perdomo-Ramirez, A., Aguirre, M., Davitaia, T., Ariceta, G., Ramos-Trujillo, E. RenalTube Group, Claverie-Martin, F., 2019. Characterization of two novel mutations in the claudin-16 and claudin-19 genes that cause familial hypomagnesemia with hypercalciuria and nephrocalcinosis. Gene 689, 227-234.

Pereira, A.C., Gray, J.D., Kogan, J.F., Davidson, R.L., Rubin, T.G., Okamoto, M. Morrison, J.H., McEwen, B.S., 2017. Age and Alzheimer's disease gene expression profiles reversed by the glutamate modulator riluzole. Mol. Psychiatry 22 296-305.

Pronker, M.F., Lemstra, S., Snijder, J., Heck, A.J., Thies-Weesie, D.M., Pasterkamp, R.J., Janssen, B.J., 2016. Structural basis of myelin-associated glycoprotein adhesion and signalling. Nat. Commun. 7, 13584.

Quarles, R.H., 2007. Myelin-associated glycoprotein (MAG): past, present and beyond. J. Neurochem. 100, 1431-1448.

Raj, T., Li, Y.I., Wong, G., Humphrey, J., Wang, M., Ramdhani, S., Wang, Y.C., Ng, B., Gupta, I., Haroutunian, V., Schadt, E.E., Young-Pearse, T., Mostafavi, S., Zhang, B. Sklar, P., Bennett, D.A., De Jager, P.L., 2018. Integrative transcriptome analyses of the aging brain implicate altered splicing in Alzheimer's disease susceptibility. Nat. Genet. 50, 1584-1592.

Sanfilippo, C., Castrogiovanni, P., Imbesi, R., Tibullo, D., Li Volti, G., Barbagallo, I. Vicario, N., Musumeci, G., Di Rosa, M., 2019. Middle-aged healthy women and Alzheimer's disease patients present an overlapping of brain cell transcriptional profile. Neuroscience 406, 333-344.

Satoh, J., Kino, Y., Asahina, N., Takitani, M., Miyoshi, J., Ishida, T., Saito, Y., 2016. TMEM119 marks a subset of microglia in the human brain. Neuropathology 36 39-49.

Shahaduzzaman, M.D., Mehta, V., Golden, J.E., Rowe, D.D., Green, S., Tadinada, R. Foran, E.A., Sanberg, P.R., Pennypacker, K.R., Willing, A.E., 2015. Human umbilical cord blood cells induce neuroprotective change in gene expression profile in neurons after ischemia through activation of Akt pathway. Cell Transplant. 24 $721-735$.

Shannon, P., Markiel, A., Ozier, O., Baliga, N.S., Wang, J.T., Ramage, D., Amin, N., Schwikowski, B., Ideker, T., 2003. Cytoscape: a software environment for integrated models of biomolecular interaction networks. Genome Res. 13 2498-2504.

Shi, M., Kovac, A., Korff, A., Cook, TJ., Ginghina, C., Bullock, K.M., Yang, L., Stewart, T., Zheng, D., Aro, P., Atik, A., Kerr, K.F., Zabetian, C.P., Peskind, E.R., Hu, S.C. Quinn, J.F., Galasko, D.R., Montine, T.J., Banks, W.A., Zhang, J., 2016. CNS tau efflux via exosomes is likely increased in Parkinson's disease but not in Alzheimer's disease. Alzheimers Dement 12, 1125-1131.

Soto, M.S., Serres, S., Anthony, D.C., Sibson, N.R., 2014. Functional role of endothelia adhesion molecules in the early stages of brain metastasis. Neuro Oncol. 16 540-551.

Spilsbury, A., Miwa, S., Attems, J., Saretzki, G., 2015. The role of telomerase protein TERT in Alzheimer's disease and in tau-related pathology in vitro. J. Neurosci. $35,1659-1674$

Taylor, A.M., Saifetiarova, J., Bhat, M.A., 2017. Postnatal loss of neuronal and glia neurofascins differentially affects node of Ranvier maintenance and myelinated axon function. Front. Cell Neurosci. 11, 11.

Vall-Palomar, M., Arévalo, J. Ariceta, G., Meseguer, A., 2018. Establishment of urinary exosome-like vesicles isolation protocol for FHHNC patients and evaluation of different exosomal RNA extraction methods. J. Transl. Med. 16, 278.

Van Houcke, J., Bollaerts, I., Geeraerts, E., Davis, B., Beckers, A., Van Hove, I. Lemmens, K., De Groef, L., Moons, L., 2017. Successful optic nerve regeneration in the senescent zebrafish despite age-related decline of cell intrinsic and extrinsic response processes. Neurobiol. Aging 60,1-10.

Volkmer, H., Leuschner, R., Zacharias, U., Rathjen, F.G., 1996. Neurofascin induces neurites by heterophilic interactions with axonal NrCAM while NrCAM 
requires F11 on the axonal surface to extend neurites. J. Cell Biol. 135, 1059-1069.

Wang, S.B., Xu, T., Peng, S., Singh, D., Ghiassi-Nejad, M., Adelman, R.A., Rizzolo, L.J., 2019. Disease-associated mutations of claudin-19 disrupt retinal neurogenesis and visual function. Commun. Biol. 2, 113.

Won, M., Lee, S., Choi, S., Ro, H., Kim, K.J., Kim, J.H., Kim, K.E., Kim, K.K., 2016. Identification and characterization of the RNA-binding protein Rbfox3 in zebrafish embryo. Biochem. Biophys. Res. Commun. 472, 373-378.

Yano, H., Motoshima, T., Ma, C., Pan, C., Yamada, S., Nakayama, T., Kitada, S., Fujimoto, N., Kamba, T. Takeya, M., Komohara, Y., 2017. The significance of TIMD4 expression in clear cell renal cell carcinoma. Med. Mol. Morphol. 50, $220-226$.
Yasen, M., Fei, Q., Hutton, W.C., Zhang, J., Dong, J., Jiang, X., Zhang, F., 2013. Changes of number of cells expressing proliferation and progenitor cell markers with age in rabbit intervertebral discs. Acta Biochim. Biophys. Sin. (Shanghai) 45, 368-376.

Young, M.D., Wakefield, M.J., Smyth, G.K., Oshlack, A., 2010. Gene ontology analysis for RNA-seq: accounting for selection bias. Genome Biol. 11, R14.

Zhang, A., Desmazieres, A., Zonta, B., Melrose, S., Campbell, G., Mahad, D., Li, Q. Sherman, D.L., Reynolds, R., Brophy, P.J., 2015. Neurofascin 140 is an embryonic neuronal neurofascin isoform that promotes the assembly of the node of Ranvier. J. Neurosci. 35, 2246-2254.

Zhou, Y., Zhou, B., Pache, L., Chang, M., Khodabakhshi, A.H., Tanaseichuk, O., Benner, C., Chanda, S.K., 2019. Metascape provides a biologist-oriented resource for the analysis of systems-level datasets. Nat. Commun. 10, 1523. 